NASA/CR-2003-211826

\title{
Ice-Accretion Scaling Using Water-Film Thickness Parameters
}

David N. Anderson

Ohio Aerospace Institute, Brook Park, Ohio

Alejandro Feo

Instituto Nacional de Technica Aerospacial, Madrid, Spain 
Since its founding, NASA has been dedicated to the advancement of aeronautics and space science. The NASA Scientific and Technical Information (STI) Program Office plays a key part in helping NASA maintain this important role.

The NASA STI Program Office is operated by Langley Research Center, the Lead Center for NASA's scientific and technical information. The NASA STI Program Office provides access to the NASA STI Database, the largest collection of aeronautical and space science STI in the world. The Program Office is also NASA's institutional mechanism for disseminating the results of its research and development activities. These results are published by NASA in the NASA STI Report Series, which includes the following report types:

- $\quad$ TECHNICAL PUBLICATION. Reports of completed research or a major significant phase of research that present the results of NASA programs and include extensive data or theoretical analysis. Includes compilations of significant scientific and technical data and information deemed to be of continuing reference value. NASA's counterpart of peerreviewed formal professional papers but has less stringent limitations on manuscript length and extent of graphic presentations.

- TECHNICAL MEMORANDUM. Scientific and technical findings that are preliminary or of specialized interest, e.g., quick release reports, working papers, and bibliographies that contain minimal annotation. Does not contain extensive analysis.

- CONTRACTOR REPORT. Scientific and technical findings by NASA-sponsored contractors and grantees.
- CONFERENCE PUBLICATION. Collected papers from scientific and technical conferences, symposia, seminars, or other meetings sponsored or cosponsored by NASA.

- SPECIAL PUBLICATION. Scientific, technical, or historical information from NASA programs, projects, and missions, often concerned with subjects having substantial public interest.

- TECHNICAL TRANSLATION. Englishlanguage translations of foreign scientific and technical material pertinent to NASA's mission.

Specialized services that complement the STI Program Office's diverse offerings include creating custom thesauri, building customized data bases, organizing and publishing research results ... even providing videos.

For more information about the NASA STI Program Office, see the following:

- Access the NASA STI Program Home Page at http://www.sti.nasa.gov

- E-mail your question via the Internet to help@sti.nasa.gov

- Fax your question to the NASA Access Help Desk at 301-621-0134

- Telephone the NASA Access Help Desk at 301-621-0390

- Write to:

NASA Access Help Desk

NASA Center for AeroSpace Information 7121 Standard Drive

Hanover, MD 21076 
NASA/CR-2003-211826

AIAA-2002-0522

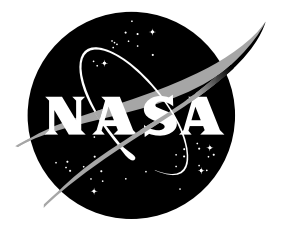

\section{Ice-Accretion Scaling Using Water-Film Thickness Parameters}

David N. Anderson

Ohio Aerospace Institute, Brook Park, Ohio

Alejandro Feo

Instituto Nacional de Technica Aerospacial, Madrid, Spain

Prepared for the

40th Aerospace Sciences Meeting and Exhibit

sponsored by the American Institute of Aeronautics and Astronautics

Reno, Nevada, January 14-17, 2002

Prepared under Cooperative Agreement NCC3-884

National Aeronautics and

Space Administration

Glenn Research Center 


\section{Acknowledgments}

The INTA, NASA Glenn Research Center Icing Branch, and the FAA contributed to the work reported here. The IRT studies were supported under a grant from NASA to the Ohio Aerospace Institute.

The authors wish to thank Jim Riley of the FAA and Tom Bond of NASA for their support of these tests and the IRT personnel for their excellent and committed technical support.

This report contains preliminary

findings, subject to revision as analysis proceeds.

The Aerospace Propulsion and Power Program at NASA Glenn Research Center sponsored this work.

Available from

NASA Center for Aerospace Information 7121 Standard Drive

Hanover, MD 21076
National Technical Information Service 5285 Port Royal Road Springfield, VA 22100 


\title{
ICE-ACCRETION SCALING USING WATER-FILM THICKNESS PARAMETERS
}

\author{
David N. Anderson* \\ Ohio Aerospace Institute \\ Brook Park, Ohio \\ Alejandro $\mathrm{Feo}^{\dagger}$ \\ Instituto Nacional de Technica Aeroespacial \\ Madrid, Spain
}

\begin{abstract}
$\underline{\text { Abstract }}$
Studies were performed at INTA in Spain to determine water-film thickness on a stagnation-point probe inserted in a simulated cloud. The measurements were correlated with non-dimensional parameters describing the flow and the cloud conditions. Icing scaling tests in the NASA Glenn Icing Research Tunnel were then conducted using the Ruff scaling method with the scale velocity found by matching scale and reference values of either the INTA non-dimensional water-film thickness or a Weber number based on that film thickness. For comparison, tests were also performed using the constant drop-size Weber number and the averagevelocity methods. The reference and scale models were both aluminum, 61-cm-span, NACA 0012 airfoil sections at $0^{\circ} \mathrm{AOA}$. The reference had a $53-\mathrm{cm}$-chord and the scale, $27 \mathrm{~cm}(1 / 2$ size $)$. Both models were mounted vertically in the center of the IRT test section. Tests covered a freezing fraction range of 0.28 to 1.0 .

Rime ice $(n=1.0)$ tests showed the consistency of the IRT calibration over a range of velocities. At a freezing fraction of 0.76 , there was no significant difference in the scale ice shapes produced by the different methods. For freezing fractions of $0.40,0.52$ and 0.61 , somewhat better agreement with the reference horn angles was typically achieved with the average-velocity and constant-film thickness methods than when either of the two Weber numbers was matched to the reference value. At a freezing fraction of 0.28 , the four methods were judged equal in providing simulations of the reference shape.
\end{abstract}

\section{$\underline{\text { Nomenclature }}$}

$A_{c} \quad$ Accumulation parameter, dimensionless

$b \quad$ Relative heat factor, dimensionless

$c \quad$ Airfoil chord, cm

*Senior Research Associate, Member

${ }^{\dagger}$ Chief, Experimental Aerodynamics

\begin{tabular}{|c|c|}
\hline$c_{p}$ & Specific heat of air, cal/g K \\
\hline$c_{p, w s}$ & $\begin{array}{l}\text { Specific heat of water at the surface tempera- } \\
\text { ture, cal/g K }\end{array}$ \\
\hline$d$ & $\begin{array}{l}\text { Cylinder diameter or twice the leading-edge } \\
\text { radius of airfoil, } \mathrm{cm}\end{array}$ \\
\hline$h$ & Water-film thickness, $\mathrm{cm}$ \\
\hline$h_{c}$ & $\begin{array}{l}\text { Convective heat-transfer coefficient, } \\
\mathrm{cal} / \mathrm{s} \mathrm{m}^{2} \mathrm{~K}\end{array}$ \\
\hline$h_{G}$ & Gas-phase mass-transfer coefficient, $\mathrm{g} / \mathrm{s} \mathrm{m}^{2}$ \\
\hline$K$ & Inertia parameter, dimensionless \\
\hline$K_{0}$ & Modified inertia parameter, dimensionless \\
\hline$L W C$ & Cloud liquid-water content, $\mathrm{g} / \mathrm{m}^{3}$ \\
\hline M & Mach number, dimensionless \\
\hline$M V D$ & Water droplet median volume diameter, $\mu \mathrm{m}$ \\
\hline$n$ & Freezing fraction, dimensionless \\
\hline$p$ & Static pressure, $\mathrm{Nt} / \mathrm{m}^{2}$ \\
\hline$p_{w}$ & Vapor pressure of water in atmosphere, $\mathrm{Nt} / \mathrm{m}^{2}$ \\
\hline$p_{w w}$ & $\begin{array}{l}\text { Vapor pressure of water at the icing surface, } \\
\mathrm{Nt} / \mathrm{m}^{2}\end{array}$ \\
\hline$r$ & Recovery factor, dimensionless \\
\hline $\operatorname{Re}$ & Reynolds number of model, dimensionless \\
\hline $\operatorname{Re}_{\delta}$ & $\begin{array}{l}\text { Reynolds number of water droplet, dimen- } \\
\text { sionless }\end{array}$ \\
\hline$t_{f}$ & Freezing temperature, ${ }^{\circ} \mathrm{C}$ \\
\hline$t_{s}$ & Surface temperature, ${ }^{\circ} \mathrm{C}$ \\
\hline$t_{s t}$ & Static temperature, ${ }^{\circ} \mathrm{C}$ \\
\hline$V$ & Air velocity, $\mathrm{m} / \mathrm{s}$ \\
\hline$W e$ & $\begin{array}{l}\text { Weber number based on droplet size and water } \\
\text { properties, dimensionless }\end{array}$ \\
\hline$W e_{c}$ & $\begin{array}{l}\text { Weber number based on model size and air } \\
\text { properties, dimensionless }\end{array}$ \\
\hline$W e_{h}$ & $\begin{array}{l}\text { Weber number based on water-film thickness } \\
\text { and water properties, dimensionless }\end{array}$ \\
\hline$\beta_{0}$ & $\begin{array}{l}\text { Collection efficiency at stagnation line, dimen- } \\
\text { sionless }\end{array}$ \\
\hline$\phi$ & Droplet energy transfer parameter, ${ }^{\circ} \mathrm{C}$ \\
\hline$\lambda$ & Droplet range, $\mathrm{m}$ \\
\hline$\lambda_{\text {Stokes }}$ & Droplet range if Stokes Law applies, $\mathrm{m}$ \\
\hline$\Lambda_{f}$ & Latent heat of freezing, cal $/ \mathrm{g}$ \\
\hline$\Lambda_{v}$ & Latent heat of condensation, cal $/ \mathrm{g}$ \\
\hline$\mu$ & Air viscosity, $\mathrm{g} / \mathrm{m} \mathrm{s}$ \\
\hline
\end{tabular}




$\begin{array}{ll}\theta & \text { Air energy transfer parameter, }{ }^{\circ} \mathrm{C} \\ \rho & \text { Air density, } \mathrm{g} / \mathrm{m}^{3} \\ \rho_{i} & \text { Ice density, } \mathrm{g} / \mathrm{m}^{3} \\ \rho_{w} & \text { Liquid water density, } \mathrm{g} / \mathrm{m}^{3} \\ \sigma_{w / a} & \text { Surface tension of water over air, dyne } / \mathrm{cm} \\ \tau & \text { Accretion time, min } \\ & \text { Introduction }\end{array}$

Since the 1940's six similarity parameters have been identified $^{1,2}$ that are important to icing scaling. They are the modified inertia parameter, $K_{0}$, defined by Langmuir and Blodgett ${ }^{3}$ to insure similarity in droplet trajectory, the accumulation parameter, $A_{c}$, to insure similarity in quantity of ice accreted, and four parameters derived from the energy balance: the freezing fraction, $n$, the water-energy transfer parameter, $\phi$, the airenergy transfer parameter, $\theta$ and the relative heat factor, $b$. The parameters $n, \phi, \theta$ and $b$ were defined by Messinger $^{4}$ and Tribus ${ }^{5}$ and are not all needed for similarity of ice accretion. The AEDC or Ruff scaling method ${ }^{2}$ matches the scale and reference values of the similarity parameters $K_{0}, A_{c}, n, \phi$ and $\theta$. It is applicable to tunnels with the capability to simulate altitude. For tunnels without pressure control, a modified Ruff method has been used in which only the parameters $K_{0}, A_{c}, n$ and $\phi$ are used. $\theta$ can also be substituted for $\phi$ when this leads to more favorable scale test conditions.

During glaze-ice accretion water does not freeze immediately in the zone of impingement. The characteristics of the resulting layer of liquid surface water are believed to influence the shape of the accreted ice to some extent and are the subject of a number of ongoing studies. Bilanin ${ }^{6}$ and Bilanin and Anderson ${ }^{7}$ advocated adding another similarity parameter, the Weber number, to scaling requirements to address surface-water effects. Two forms of the Weber number that might be applied include that based on the droplet $M V D$ and water properties $(W e)$ and one based on model size and air properties $\left(W e_{c}\right)$. A third Weber number was suggested by Kind $^{8,9,10}$; this one was based on the thickness of the water film at the leading edge $\left(W e_{h}\right)$.

Anderson and Ruff ${ }^{11}$ and Anderson ${ }^{12}$ reported the best scaling results for glaze ice were achieved when a compromise between constant $W e$ and constant $R e$ was used with the modified Ruff method. This approach has been called the average-velocity method. A possible explanation for the success of this method comes from the dependence of surface-tension effects on both We and $R e$. For example, studies of droplet-surface impact $^{13}$ for non-icing applications found that splashing effects correlated with a $K$ factor depending only on $W e$ and $R e_{\delta}$. Other surface-tension effects such as waterfilm breakup and rivulet formation are also $W e$ and $R e$ dependent.
Finally, in a recent study at above-freezing temperatures, Feo and Urdiales ${ }^{14}$ measured the water-film thickness, $h$, for heavy-rain conditions. The nondimensional film thickness, $h / d$, was found to correlate with $W e$ and $R e_{\delta}$. The authors suggested that $h / d$ might itself serve as an appropriate similarity parameter for scaling studies. Although spray characteristics for that study were very different from Appendix-C conditions, the heavy-rain $h / d$ was evaluated as a similarity parameter in studies comparing how methods to select scale velocity affected ice shape. ${ }^{11,12}$ However, matching the scale and reference $h / d$ of Feo and Urdiales gave scale ice shapes that were generally a poorer match of the reference than did other methods of finding scale velocity. Later, Feo ${ }^{15}$ measured the thickness of the water film for $M V D$ and $L W C$ conditions closer to those in an icing cloud and established that the new results correlated with $L W C$ and $R e$. With the availability of this new correlation for $h / d$, the constant-water-film thickness method needed to be reevaluated. This evaluation was a goal of the present study, along with the evaluation of the constant-Weber-number based on this water-film thickness, $W e_{h}$.

In this investigation, ice accretion scaling for a model size reduction of $1 / 2$ was evaluated. The Ruff method provided the scale test conditions $t_{s t}, M V D, L W C$ and $\tau$. The scale $V$ was found by matching $W e, W e_{h}$ or $h / d$ to the respective reference value or by using the average- $V$ method. The study compared how well the scaled ice shapes agreed with the reference shapes to evaluate each of these methods of determining scale velocity.

This paper will briefly describe the recent nearAppendix $\mathrm{C}$ water-film thickness studies at INTA as well as the scaling tests performed in the NASA Glenn Icing Research Tunnel (IRT). The reference model for the scaling tests was an aluminum 61-cm-span, 53-cmchord NACA 0012 airfoil at $0^{\circ} \mathrm{AOA}$. The scale model was also an aluminum 61-cm-span model but with a chord of $27 \mathrm{~cm}$. Both models were mounted vertically in the center of the IRT test section. Test conditions covered a range of freezing fractions from 0.28 to 1.0 .

\section{Scaling Method}

The basis of the scaling used in this study was the Ruff ${ }^{2}$ method. Ruff demonstrated that the best scaling occurred when the five similarity parameters, $K_{0}, A_{c}, n, \phi$ and $\theta$, were used. The matching of each of these scale parameters to its respective reference value allows the solution for scale $M V D$, time, $L W C$, temperature and pressure. For tunnels without control of test-section pressure, either of the parameters $\phi$ or $\theta$ can be used to find scale temperature ${ }^{12}$, with the other parameter ignored. The choice of scale velocity is left to the user. 
The modified inertia parameter, $K_{0}$, was defined by Langmuir and Blodgett: ${ }^{3}$

$$
K_{0}=\frac{1}{8}+\frac{\lambda}{\lambda_{\text {Stokes }}}\left(K-\frac{1}{8}\right)
$$

A match of scale and reference $K_{0}$ insures similarity of droplet trajectories. In equation (1), $\lambda / \lambda_{\text {Stokes }}$ is the droplet range parameter, defined as the ratio of actual droplet range to that if Stokes drag law for solidspheres applied. It is a function only of the droplet Reynolds number, $R e_{\delta}$ and was tabulated by Langmuir and Blodgett. $K$ is the inertia parameter,

$$
K=\frac{\rho_{w} M V D^{2} V}{18 d \mu}
$$

Here $d$ is the diameter for cylindrical models or twice the leading-edge radius for airfoils. For the NACA 0012 , a leading-edge radius of $0.0158 c$ was used, where $c$ is the model chord.

The accumulation parameter is:

$$
A_{c}=\frac{L W C V \tau}{d \rho_{i}}
$$

A match of scale and reference $A_{c}$ insures that the same quantity of ice, relative to airfoil size, is accreted for both. This matching assumes that the leading-edge collection efficiency, $\beta_{0}$, for scale and reference situations are also equal. However, because $\beta_{0}$ is a function only of $K_{0}$, if $K_{0}$ is matched, so too is $\beta_{0}$.

The freezing fraction, from Messinger' ${ }^{4}$ surface energy balance, can be written in the form,

$$
n=\frac{c_{p, w s}}{\Lambda_{f}}\left(\phi+\frac{\theta}{b}\right)
$$

Thus, a match of scale and reference $n$ insures the overall energy balance will agree. The individual terms in this expression are $\phi$, the water energy transfer parameter; $\theta$, the air energy transfer parameter; and $b$, the relative heat factor, introduced by Tribus, et al. ${ }^{5}$ These parameters are defined as

$$
\begin{gathered}
\varphi=t_{f}-t_{s t}-\frac{V^{2}}{2 c_{p, w s}} \\
\theta=\left(t_{s}-t_{s t}-\frac{r V^{2}}{2 c_{p}}\right)+\frac{h_{G}}{h_{c}}\left(\frac{p_{w w}-p_{w}}{p}\right) \Lambda_{v} \\
b=\frac{L W C V \beta_{0} c_{p, w s}}{h_{c}}
\end{gathered}
$$

Equation (6) gives the form of $\theta$ used by Charpin ${ }^{1}$ and others. A somewhat more complex form was presented by Ruff, ${ }^{2}$ and Ruff's expression for $\theta$ was used in the calculations in this paper. The values from the two expressions are not significantly different, however.

Four ways to determine scale velocity were evaluated as supplements to the Ruff method. They involved either the inclusion of one additional similarity parameter, or the calculation of scale velocity as the average of that required to match scale and reference $W e$ and that to match $R e$. The additional parameter was either $W e$, $W e_{h}$, or $h / d$. The $W e, W e_{h}$ and $R e$ are defined as

$$
\begin{gathered}
W e=\frac{V^{2} M V D \rho_{w}}{\sigma_{w / a}} \\
W e_{h}=\frac{V^{2} h \rho_{w}}{\sigma_{w / a}} \\
R e=\frac{V d \rho}{\mu}
\end{gathered}
$$

The Feo correlation for the parameter $h / d$ will be given in the next section.

\section{INTA Water-Film-Thickness Measurements}

The water-film-thickness experiments were performed by $\mathrm{Feo}^{15}$ in the INTA 2.8-by-1.7-m wind tunnel shown in figure 1 . The water spray was generated using a single air-atomizing nozzle located in the open test section as seen in figure 1(a). The target probe was positioned at the entrance to the bell mouth. Three nozzles were used, Spraying Systems models SUJ 12 A, SUJ 12 and SUJ 22 B. These operated at different air and water pressures and therefore provided some check on the validity of the relationship between film-thickness and

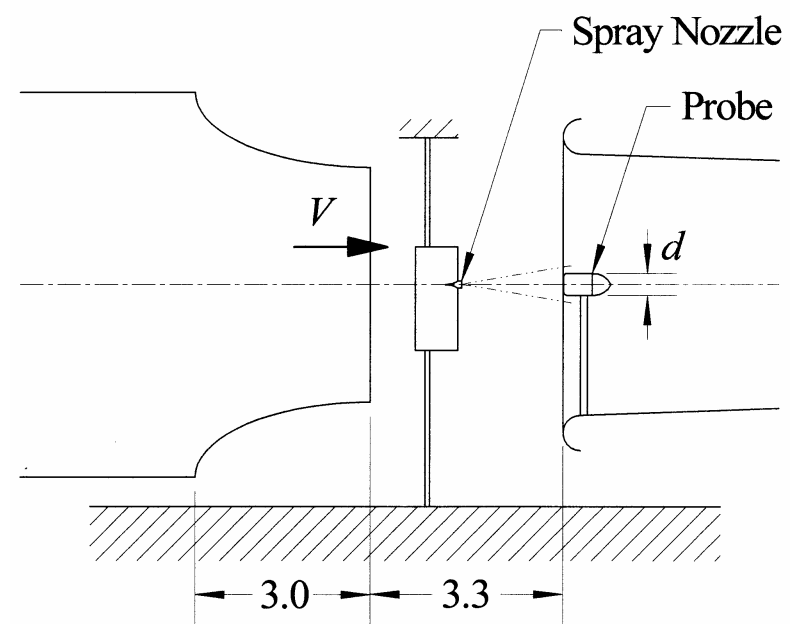

(a) Water Spray and Probe. Dimensions are in $\mathrm{m}$.

Figure 1. INTA Wind Tunnel. 
cloud conditions. Correlations of the nozzle air and water pressures with cloud characteristics at the position of the film-measuring stagnation-point probe were obtained by testing with an OAP-200 probe to determine $M V D$ and a water-collection probe to measure $L W C$. The nozzle spray can be seen in figure 1(b).

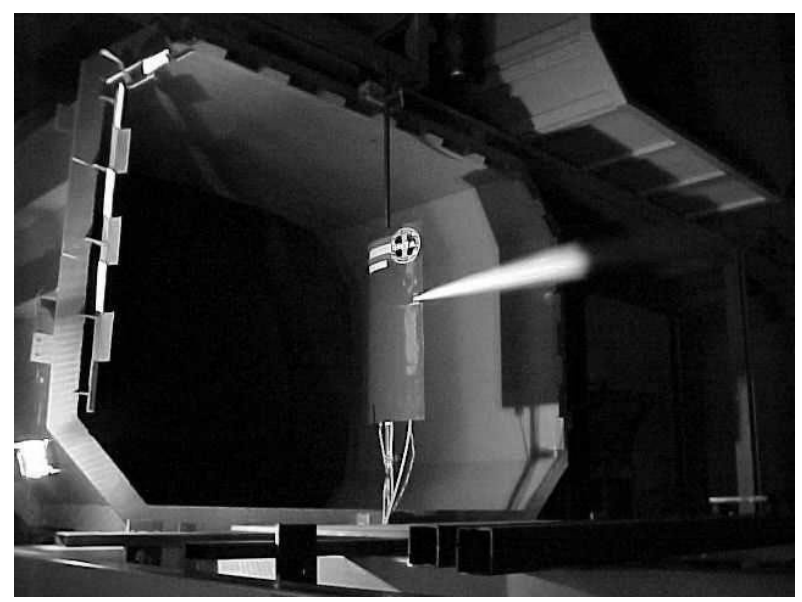

(b) Test section with spray.

Figure 1. Concluded.

Sixteen tests were performed; the test conditions are given in table I. The OAP-200 instrument measured droplet sizes no smaller than $25 \mu \mathrm{m}$; thus, Appendix-C $M V D$ 's could not be accurately determined. It was insensitive to the sprays generated by the nozzles SUJ 12 and SUJ $12 \mathrm{~A}$, suggesting that MVD's were below $25 \mu \mathrm{m}$ for these. In two cases, the pressures used with these nozzles corresponded with the manufacturer's published tests, and these are reported in table I as $M V D$ 's of 13 and $15 \mu \mathrm{m}$. Test $M V D$ 's, then, covered a range from well under 25 to $160 \mu \mathrm{m}$.

$L W C$ 's for this study were higher than desired to simulate Appendix-C clouds, but it was hoped that correlations developed from these data could be extrapolated to Appendix-C conditions. The tests were made at ambient temperatures well above freezing, representing a freezing fraction of zero.

A conductance sensor mounted flush in the front face of a cylindrical stagnation-point probe was used to determine water-film thickness. A cross-section sketch of the probe ${ }^{14}$ is shown in figure 2 with a water-film of thickness $h$ indicated conceptually. The probe was located $2.5 \mathrm{~m}$ downstream from the water nozzle. A detailed description of the conductance sensor is given in Feo and Urdiales ${ }^{14}$ and Feo, Rogles and Urdiales. ${ }^{16}$

Table I lists the measured water-film thicknesses reported in reference 15 . The uncertainty in these data is estimated to be $\pm 20 \%$. They have been nondimensionalized and plotted in figure 3. Note that
Table I

Film-Thickness Test Conditions and Results

\begin{tabular}{|c|c|c|c|c|}
\hline Nozzle & $\begin{array}{c}V, \\
\mathrm{~m} / \mathrm{s}\end{array}$ & $\begin{array}{c}M V D \\
\mu \mathrm{m}\end{array}$ & $\begin{array}{l}L W C, \\
\mathrm{~g} / \mathrm{m}^{3}\end{array}$ & $\begin{array}{c}h, \\
\mu \mathrm{m}\end{array}$ \\
\hline SUJ 12 A & 55 & 13 & 5.39 & 75 \\
\hline SUJ 12 A & 55 & $<25$ & 4.84 & 62 \\
\hline SUJ 12 A & 30 & $<25$ & 4.53 & 79 \\
\hline SUJ $12 \mathrm{~A}$ & 30 & $<25$ & 6.69 & 108 \\
\hline SUJ $12 \mathrm{~A}$ & 20 & $<25$ & 6.99 & 95 \\
\hline SUJ $12 \mathrm{~A}$ & 20 & $<25$ & 5.17 & 89 \\
\hline SUJ 12 & 55 & 15 & 5.25 & 60 \\
\hline SUJ 12 & 55 & $<25$ & 4.22 & 65 \\
\hline SUJ 12 & 55 & $<25$ & 2.65 & 55 \\
\hline SUJ 12 & 30 & $<25$ & 6.41 & 72 \\
\hline SUJ 12 & 20 & $<25$ & 7.79 & 106 \\
\hline SUJ 12 & 20 & $<25$ & 8.45 & 125 \\
\hline SUJ 12 & 20 & $<25$ & 4.97 & 103 \\
\hline SUJ 22 B & 55 & 160 & 10.67 & 106 \\
\hline SUJ $22 \mathrm{~B}$ & 30 & 160 & 9.00 & 118 \\
\hline SUJ 22 B & 20 & 88 & 14.54 & 154 \\
\hline
\end{tabular}

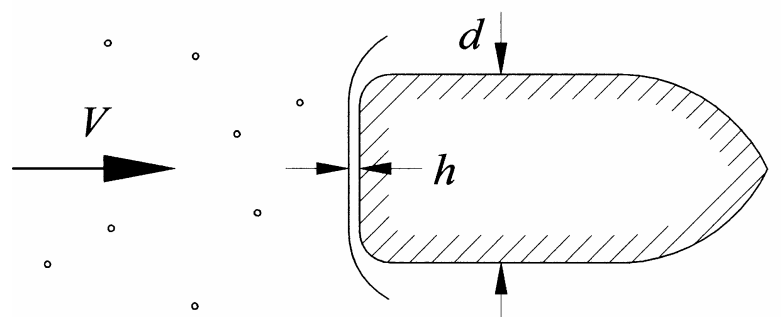

Figure 2. Stagnation-Point Probe with Water Film.

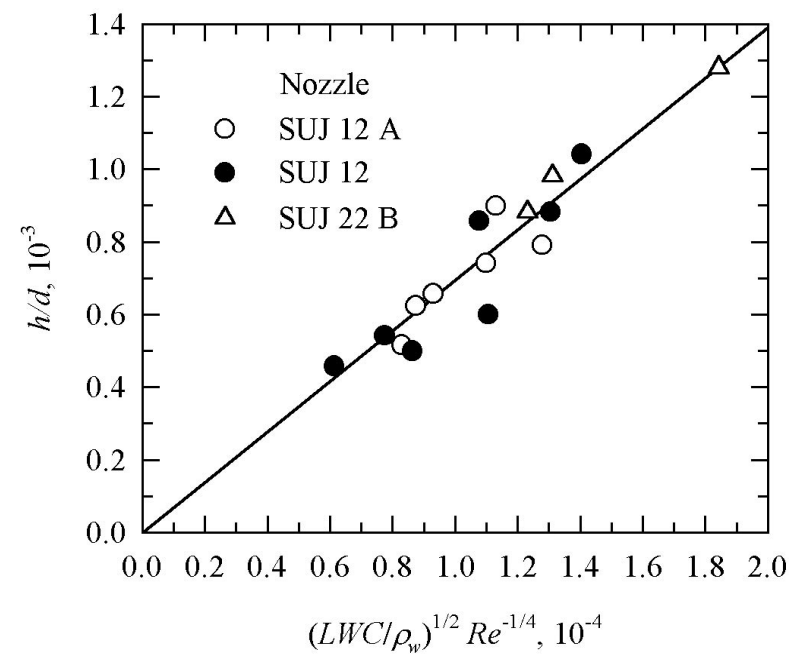

Figure 3. Film-Thickness Correlation. 
because of the $R e$ dependency, the slope of the line will be affected slightly by test ambient pressure and temperature. The best correlation of the experimental film thickness data was found to be

$$
h / d \propto\left(\frac{L W C}{\rho_{w}}\right)^{1 / 2} R e^{-1 / 4}
$$

This expression shows no water surface-tension effects, indicating that for the spray conditions and the stagnation probe geometry used, droplet impacts, film breakup and rivulet formation are not important. However, measurements on the stagnation point on a cylinder or airfoil might show a different behavior.

Figure 3 shows that data for all three nozzles correlated well with the right-hand side of equation (11). The proportionality constant that should appear on the right side of equation (11) is not known for icing conditions at this time. However, it must be some function of the freezing fraction, because at a freezing fraction of unity, there is no water film, while at a freezing fraction of zero, the thickness $h$ would apply. Furthermore, different constants may be required for Appendix-C conditions than for the $L W C$ 's of this study. The form of equation (11) has been verified analytically by Rothmayer ${ }^{17}$ for the range of temperatures and spray conditions of the INTA tests.

The INTA tests provided two similarity parameters: the non-dimensional water-film thickness, $h / d$, and the Weber number using this film thickness as the length scale, $W e_{h}$, defined in equation (9). These parameters were evaluated for their use in scaling in the IRT scaling tests described next.

\section{IRT Scaling Test Description}

The scaling tests were performed in the NASA Glenn IRT. The IRT is a closed-loop, refrigerated, sea level tunnel with a test section of 1.8 by $2.7 \mathrm{~m}$. The tunnel loop is shown in figure 4(a). The IRT has 10 spray bars. In the summer of 2000 , a complete cloud calibration $^{18}$ for both the mod-1 and standard nozzles was completed following the installation of a new heat exchanger and other upgrades. ${ }^{19}$

The models used for these tests were NACA 0012 61cm-span aluminum airfoil sections with chords of 53.3 and $26.7 \mathrm{~cm}$. They were mounted vertically between splitter plates at the center of the IRT test section as shown typically in figure 4(b). Horizontal lines at the leading edge indicated tunnel center, $\pm 2.5 \mathrm{~cm}$ and \pm 5 $\mathrm{cm}$ from the center as guides for locating ice tracings. The mounting arrangement permitted rotation of the model for angle of attack changes, but all tests were run at $0^{\circ}$ AOA. The IRT spray system has rapid-start capability; consequently, the model did not require shielding during spray initiation.

In preparing for a test, the temperature and airspeed in the test section and the air and water pressures on the spray manifolds were set. When these conditions had stabilized, the spray nozzle valves were opened to initiate the spray. The spray was timed for the required duration, and then turned off. The fan was brought to a full stop and the tunnel entered to record the ice shape. A heated ice knife with a cutout in the shape of the model was inserted into the leading edge of the ice to melt a thin slice down to the model surface. A card-

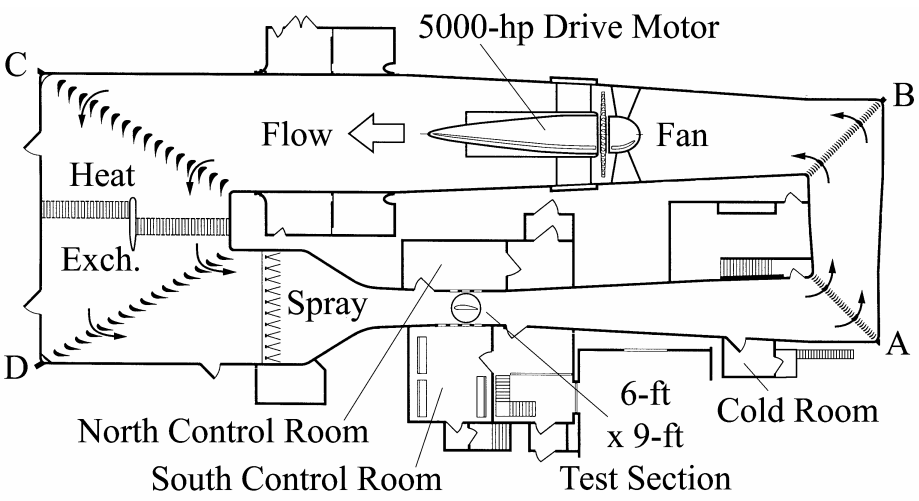

(a) NASA Glenn Icing Research Tunnel. Revised Loop with New Heat Exchanger Installed in 2000.

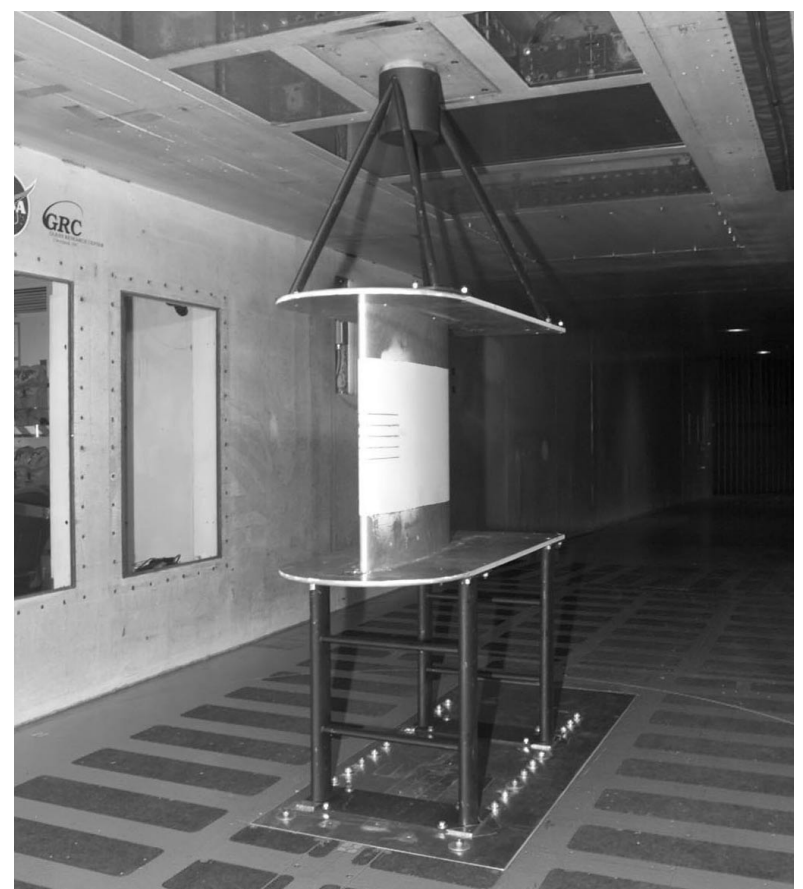

(b) Model Installed in IRT Test Section.

Figure 4. Facility and Model Description. 
board template was placed into this gap and an outline of the ice accretion traced. Tracings were taken at the vertical center of the tunnel $(91 \mathrm{~cm}$ from the floor) and at $2.5 \mathrm{~cm}$ above the center. Ice shape differences between the two tracing locations were never significant, and only centerline shapes will be reported here. The tracings were digitized and the $x-y$ coordinates for each ice shape recorded. When plots of ice-shapes were compared for different sized models, the coordinates were normalized by the model chord.

Reference test conditions were chosen so that both reference and scale conditions would fall within the IRT operating envelope. The six cases selected all had the same $V, M V D, L W C$ and $\tau$ but with temperatures varied to provide a range of freezing fractions from 0.28 to 1.0. Scale conditions for $1 / 2$-size scaling were determined as discussed above. It turned out that the constant- $W e$ and constant- $W e_{h}$ methods of finding scale velocity gave virtually the same scale test conditions, thus, there were only three distinct sets of scale conditions for each reference case. Nevertheless, tests for both the constant- $W e$ and constant- $W e_{h}$ methods were made so that repeatability could be evaluated. Results from three test entries-August 2000, November 2000 and March 2001—will be presented. Only a sampling of typical results will be shown.

\section{Uncertainty Analysis for IRT}

Tunnel and cloud conditions were recorded every $1 \mathrm{sec}$ over the duration of each test for the August and November 2000 entries. For the March 2001 tests the recording interval was $3 \mathrm{sec}$. Reported conditions are the time averages of these records. Estimates of the uncertainty in the reported average conditions were made by considering fluctuations of the values over time, possible instrument errors, uncertainties in tunnel calibration of $M V D$ and $L W C$ and differences in measurements from one location to another in the test section.

Total temperature was measured as the average of the readings of 24 thermocouples located on the D-corner turning vanes. Including inherent uncertainty in the thermocouples themselves, it is estimated that the total uncertainty in temperature is on the order of $\pm 0.5^{\circ} \mathrm{C}$.

Test-section velocity was determined from the average total and average static pressures from 2 pitot-static probes, one located on the north wall and one on the south wall of the tunnel at the entrance to the test section. The maximum computed difference in velocities indicated by the two probes was $\pm 0.25 \%$. Pressures also fluctuated modestly with time such that the maximum variation in velocity over the spray duration was determined to be $\pm 1.3 \mathrm{~m} / \mathrm{s}$ at an average velocity of 40 $\mathrm{m} / \mathrm{s}$ and $\pm 1 \mathrm{~m} / \mathrm{s}$ for speeds higher than $40 \mathrm{~m} / \mathrm{s}$.
The most significant contribution to $L W C$ uncertainty is the calibration process, and scatter in the calibration data suggests this uncertainty is about $\pm 10 \%$.

The largest contribution to drop-size uncertainty comes from the instrument used in calibration and was estimated from the observed randomness recorded during calibration. The net uncertainty in $M V D$ is estimated at $\pm 12 \%$. This uncertainty applies only to the particular instruments used (OAP and FSSP probes) in the IRT calibration and do not suggest a reference to any absolute value of $M V D$, because the absolute value is not known.

These uncertainties in the test parameters produce the following approximate uncertainties in the similarity parameters for the tests reported here: $17 \%$ in $K_{0}, 2 \%$ in $\beta_{0}, 12 \%$ in $A_{c}, 15 \%$ in $n, 1{ }^{\circ} \mathrm{C}$ each in $\phi$ and $\theta, 2 \%$ in $R e, 12 \%$ in $W e, 7 \%$ in $W e_{h}$, and $6 \%$ in $h / d$. For the last two parameters, uncertainties are in the relative values calculated with the correlation of equation (11).

\section{$\underline{\text { Scaling Results }}$}

Figures 5 to 11 present the non-dimensional scale and reference ice shapes recorded using each method of finding scale velocity. Each figure represents a different reference case. Reference ice shapes are shown shaded, while the scale shapes are indicated by a solid line. The table below each figure gives the test conditions and similarity parameters for each pair of reference and scale tests. The conditions given are the average conditions recorded over the duration of each test, which can sometimes differ slightly from the planned set points. The parameters in the tables were calculated from these average conditions. The numbers in the last column in the table are not actual water-film thicknesses but rather the relative $h / d$. This value was calculated from the right-hand side of equation (11).

\section{$\underline{\text { Scaling Repeatability-Figures } 5 \text { and } 6}$}

Figures 5 and 6 each compare two sets of reference and scale tests for half-size scaling. Two of these used the average- $V$ method of determining scale velocity, and two used constant-We or constant- $W e_{h}$. As noted above, these latter methods produce almost identical scale test conditions. The freezing fraction was 0.28 for the average- $V$ tests (figs. 5(a) and (b)), which were performed in August and November 2000, and 0.52 for the constant- $W e$ and constant- $W e_{h}$ tests (figs. 6(a) and (b)), which were made in November 2000 and March 2001.

In the August 2000 average- $V$ tests, (fig. 5(a)) the scale ice shape closely matched the reference in terms of the main ice accretion size and shape as well as the feather structure aft of the main shape. When the same reference and scale test conditions were repeated in the 


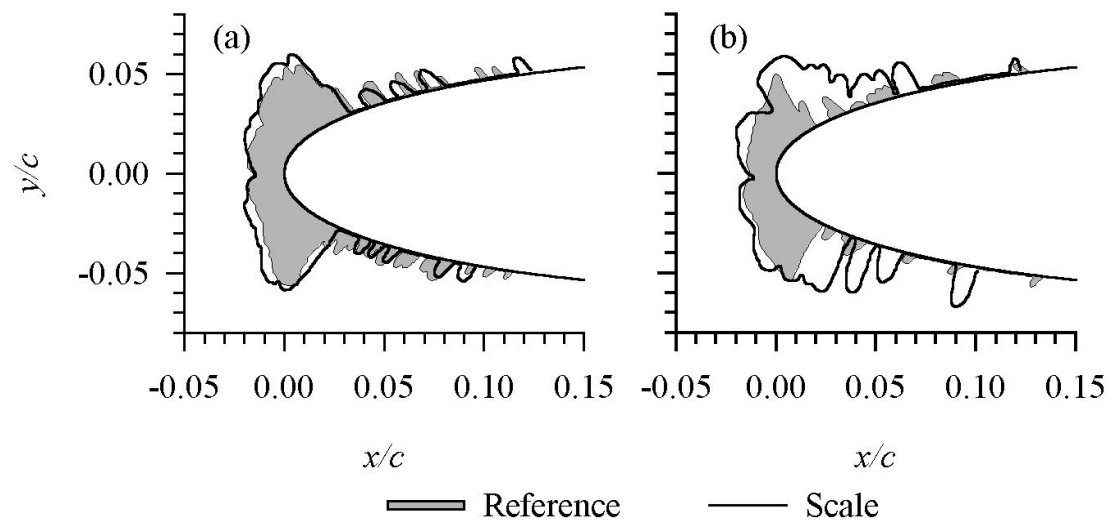

uncertainties in temperature or $L W C$ from run to run can make a significant difference in ice shape.

Large differences in shape are usually not seen when the freezing fraction is higher than about 0.3 . Figure 6 shows some typical repeatability results for a nominal freezing fraction of 0.5 . The reference ice shapes shown in figures 6(a) and (b) had consistent horn angles and ice quantity, as did

\begin{tabular}{|c|c|c|c|c|c|c|c|c|c|c|c|c|c|c|c|c|c|}
\hline $\begin{array}{l}\text { Scaling } \\
\text { Method }\end{array}$ & Date/Run & $\begin{array}{l}c, \\
\mathrm{~cm}\end{array}$ & $\begin{array}{l}t_{s t}, \\
{ }^{\circ} \mathrm{C}\end{array}$ & $\begin{array}{c}V, \\
\mathrm{~m} / \mathrm{s}\end{array}$ & $\begin{array}{c}M V D \\
\mu \mathrm{m}\end{array}$ & $\begin{array}{l}L W C, \\
\mathrm{~g} / \mathrm{m}^{3}\end{array}$ & $\underset{\min }{\tau}$ & $K_{0}$ & $\begin{array}{l}\beta_{0}, \\
\%\end{array}$ & $A_{c}$ & $n$ & $\begin{array}{l}\phi, \\
{ }^{\circ} \mathrm{C}\end{array}$ & $\begin{array}{l}\theta, \\
{ }^{\circ} \mathrm{C}\end{array}$ & $\begin{array}{l}\text { Re, } \\
10^{4}\end{array}$ & $\begin{array}{l}\text { We, } \\
10^{3}\end{array}$ & $W e_{h}$ & $\begin{array}{l}\text { rel } \\
h / d\end{array}$ \\
\hline (a) Ref & $8-8-00 / 1$ & 53.3 & -7 & 67 & 40 & 1.00 & 7.3 & 5.7 & 86 & 1.90 & 0.28 & 7 & 9 & 8.6 & 2.8 & 68 & 5.8 \\
\hline $\operatorname{Avg} V$ & $8-10-00 / 6$ & 26.7 & -11 & 115 & 21 & 1.21 & 1.8 & 5.8 & 86 & 1.95 & 0.30 & 9 & 10 & 7.1 & 4.3 & 116 & 6.8 \\
\hline (b) Ref & $11-13-00 / 2$ & 53.3 & -7 & 67 & 38 & 1.00 & 7.3 & 5.3 & 85 & 1.88 & 0.28 & 7 & 9 & 8.6 & 2.6 & 68 & 5.8 \\
\hline $\operatorname{Avg} V$ & $11-16-00 / 2$ & 26.7 & -10 & 114 & 21 & 1.20 & 1.8 & 5.8 & 86 & 1.87 & 0.29 & 9 & 9 & 7.1 & 4.2 & 114 & 6.7 \\
\hline
\end{tabular}

Figure 5. Ice Shape Repeatability at a Nominal Freezing Fraction of 0.3.

November 2000 entry (fig. 5(b)), the results showed significant differences between the reference and scale shapes. In particular, the scale shape appears to have been formed at a lower freezing fraction than the reference. Figures 5(a) and (b) illustrate how variable ice shapes can be for low freezing fraction conditions. At freezing fractions as low as 0.28 , variations within the

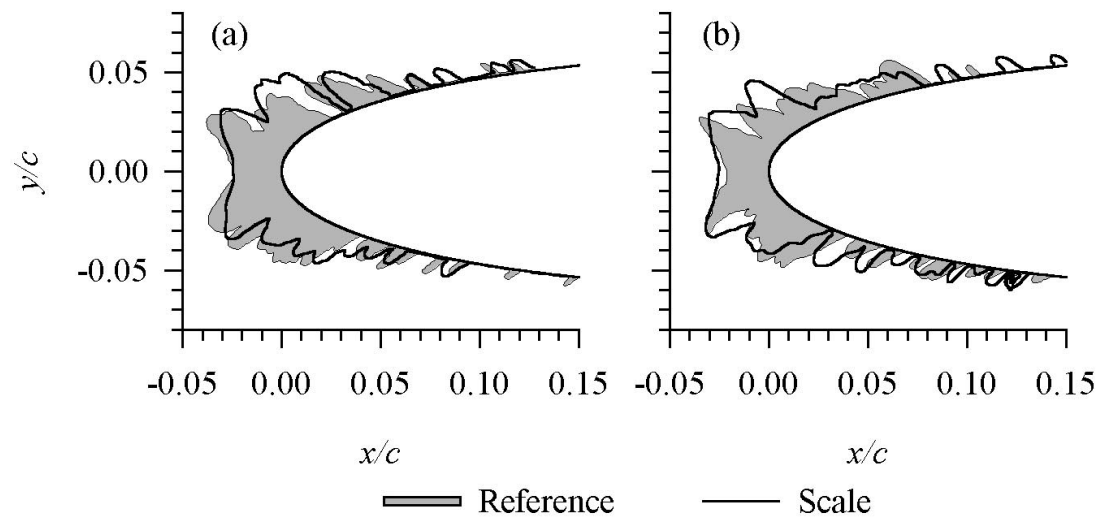

the two scale shapes. The results from the November 2000 (fig. 6(a)) and March 2001 (fig. 6(b)) test entries were sufficiently different, however, that the nondimensional reference shape in figure 6(a) was slightly larger than the scale, while the scale in figure 6(b) appeared to be slightly larger than the reference. These differences in quantities are consistent with the uncertainty in test parameters. Thus, when comparing normalized scale and reference ice shapes it is important to consider test uncertainties and not expect precise matches.

\section{$\underline{\text { Rime (Case 460)-Figure } 7}$}

For rime ice, the heat transfer rate is high enough that water freezes immediately on impact with the surface. Thus, for scaling analyses, heat transfer or surface water expressions are unnecessary, and

\begin{tabular}{|c|c|c|c|c|c|c|c|c|c|c|c|c|c|c|c|c|c|}
\hline $\begin{array}{l}\text { Scaling } \\
\text { Method }\end{array}$ & Date/Run & $\begin{array}{l}c, \\
\mathrm{~cm}\end{array}$ & $\begin{array}{l}t_{s t}, \\
{ }^{\circ} \mathrm{C}\end{array}$ & $\begin{array}{c}V, \\
\mathrm{~m} / \mathrm{s}\end{array}$ & $\begin{array}{c}M V D, \\
\mu \mathrm{m}\end{array}$ & $\begin{array}{c}L W C, \\
\mathrm{~g} / \mathrm{m}^{3}\end{array}$ & $\underset{\min }{\tau}$ & $K_{0}$ & $\begin{array}{l}\beta_{0}, \\
\%\end{array}$ & $A_{c}$ & $n$ & $\begin{array}{l}\phi, \\
{ }^{\circ} \mathrm{C}\end{array}$ & $\begin{array}{c}\theta, \\
{ }^{\circ} \mathrm{C}\end{array}$ & $\begin{array}{l}\text { Re } \\
10^{4}\end{array}$ & $\begin{array}{l}\text { We } \\
10^{3}\end{array}$ & $W e_{h}$ & $\begin{array}{l}\text { rel } \\
h / d\end{array}$ \\
\hline (a) Ref & $11-13-00 / 5$ & 53.3 & -13 & 67 & 38 & 0.99 & 7.3 & 5.3 & 85 & 1.88 & 0.52 & 12 & 17 & 8.9 & 2.6 & 67 & 5.8 \\
\hline Const $W e$ & $11-16-00 / 7$ & 26.7 & -13 & 88 & 23 & 1.14 & 2.4 & 5.7 & 86 & 1.89 & 0.51 & 12 & 16 & 5.7 & 2.8 & 69 & 6.9 \\
\hline (b) Ref & $3-20-01 / 5$ & 53.3 & -13 & 67 & 40 & 1.00 & 7.3 & 5.7 & 86 & 1.89 & 0.52 & 12 & 17 & 8.8 & 2.8 & 67 & 5.8 \\
\hline Const $W e_{h}$ & $3-22-01 / 7$ & 26.7 & -13 & 86 & 24 & 1.16 & 2.4 & 5.8 & 86 & 1.86 & 0.52 & 12 & 16 & 5.6 & 2.7 & 67 & 7.0 \\
\hline
\end{tabular}

Figure 6. Ice Shape Repeatability at a Nominal Freezing Fraction of 0.5. 
any method of choosing scale velocity should be equally valid.

Although they serve no purpose in evaluating scaling methods, rime tests can be used to validate tunnel calibrations because the different methods of choosing scale velocity result in a range of scale velocity and $L W C$. While the scale test conditions are different from method to method, they should all produce the same rime shape and quantity.

Figure 7 shows the comparison of scale and reference shapes for three methods of determining scale velocity: constant $W e$, constant $W e_{h}$ and constant $h / d$. Remember that for rime ice $h / d=0$, so the values in the $h / d$ column in the table have no physical meaning. Nevertheless, scale velocities found by matching scale and reference relative $h / d$ are valid for use even in rime studies.

In figures 7(a) and (b) the scale ice shapes simulated the reference well with regard to both shape and quantity of ice accreted. Even the feather region was well matched. The test of the constant- $h / d$ method (fig. 7(c)), produced scale accretions with the right shapes, but with smaller quantity than the reference. Since the uncertainty in $L W C$ has been estimated to be $\pm 10 \%$, differences in ice quantity from one test to another should be within about $20 \%$. The differences observed in figure $7(\mathrm{c})$ appear to be of about this magnitude.
Freezing Fraction of 0.76 (Case 461)-Figure 8

For a freezing fraction of 0.76 , only the constant- $W e$ (fig. 8(a)), constant- $W e_{h}$ (fig. 8(b)) and constant- $h / d$ methods (fig. 8(c)) were tested. All three methods gave approximately the same quantity of scale ice and nearly the same shape. Feather growth aft of the leading edge was well simulated by all methods tested.

Freezing Fraction of 0.52 (Case 463)_Figure 9

Shape differences among the different methods are more evident when the freezing fraction is reduced sufficiently to produce glaze horns. Horns were evident in tests at a freezing fraction of 0.6. Scaling results at this freezing fraction were essentially the same as those at a freezing fraction of 0.52 , shown in figure 9, with the average- $V$ and constant- $h / d$ methods providing scale shapes that were good simulations of the reference.

For $n=0.52$, all four methods of determining scale velocity were tested. Because, as noted above, the constant- $W e$ and constant- $W e_{h}$ methods produced virtually the same scale test conditions, only the constant- $W e_{h}$ results are shown in figure 9(a) for comparison with the average- $V$ (fig. 9(b)) and constant- $h / d$ results (fig. 9(c)). Neither the constant- $W e$ nor the constant- $W e_{h}$ methods were able to simulate the glaze horn angle, although both produced the correct quantity of ice and reproduced well the feather size and density.

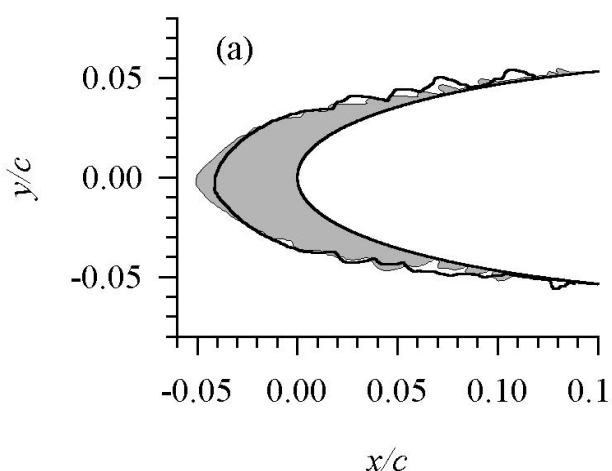

$x / c$
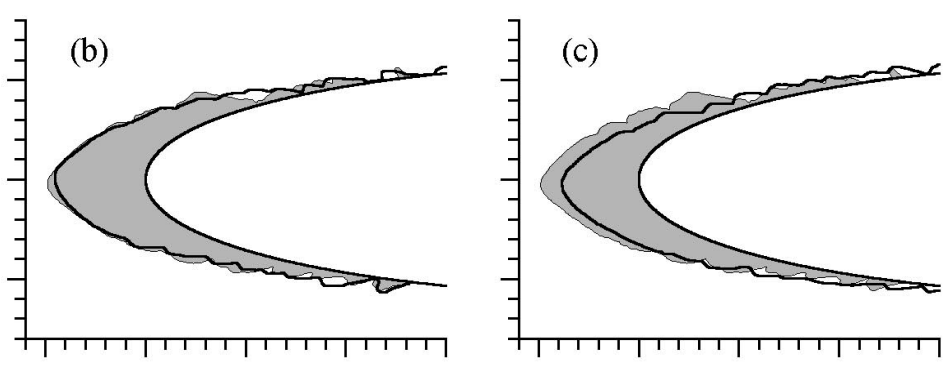

$-0.0$ \begin{tabular}{llllll}
\hline & -0.05 & 0.00 & 0.05 & 0.10 & 0.15
\end{tabular}

$x / c$

$x / c$

\begin{tabular}{|c|c|c|c|c|c|c|c|c|c|c|c|c|c|c|c|c|c|}
\hline & & & & & & & & & & & & & & & & & \\
\hline $\begin{array}{l}\text { Scaling } \\
\text { Method }\end{array}$ & Date/Run & $\begin{array}{l}c, \\
\mathrm{~cm}\end{array}$ & $\begin{array}{l}t_{s t}, \\
{ }^{\circ} \mathrm{C}\end{array}$ & $\begin{array}{c}V, \\
\mathrm{~m} / \mathrm{s}\end{array}$ & $\begin{array}{c}M V D, \\
\mu \mathrm{m}\end{array}$ & $\begin{array}{c}L W C, \\
\mathrm{~g} / \mathrm{m}^{3}\end{array}$ & $\underset{\min }{\tau}$ & $K_{0}$ & $\begin{array}{l}\beta_{0}, \\
\%\end{array}$ & $A_{c}$ & $n$ & $\begin{array}{l}\phi \\
{ }^{\circ} \mathrm{C}\end{array}$ & $\begin{array}{c}\theta, \\
{ }^{\circ} \mathrm{C}\end{array}$ & $\begin{array}{l}\text { Re, } \\
10^{4}\end{array}$ & $\begin{array}{l}W e, \\
10^{3}\end{array}$ & $W e_{h}$ & $\begin{array}{l}\text { rel } \\
h / d\end{array}$ \\
\hline (a) Ref & $11-13-00 / 8$ & 53.3 & -27 & 67 & 38 & 0.99 & 7.3 & 5.3 & 85 & 1.88 & 1.0 & 26 & 34 & 9.8 & 2.6 & 65 & 5.6 \\
\hline Const $W e$ & $11-16-00 / 15$ & 26.7 & -27 & 88 & 23 & 1.18 & 2.4 & 5.8 & 86 & 1.88 & 1.0 & 26 & 32 & 6.3 & 2.8 & 68 & 6.9 \\
\hline (b) Ref & $3-21-01 / 4$ & 53.3 & -26 & 67 & 40 & 1.00 & 7.3 & 5.7 & 86 & 1.89 & 1.0 & 26 & 33 & 9.6 & 2.7 & 65 & 5.7 \\
\hline Const $W e_{h}$ & $3-22-01 / 1$ & 26.7 & -26 & 86 & 24 & 1.20 & 2.4 & 5.8 & 86 & 1.91 & 1.0 & 26 & 32 & 6.1 & 2.7 & 66 & 7.0 \\
\hline (c) Ref & $3-21-01 / 4$ & 53.3 & -26 & 67 & 40 & 1.00 & 7.3 & 5.7 & 86 & 1.89 & 1.0 & 26 & 33 & 9.6 & 2.7 & 65 & 5.7 \\
\hline Const $h / d$ & $3-22-01 / 2$ & 26.7 & -27 & 117 & 21 & 0.93 & 2.2 & 5.8 & 86 & 1.87 & 1.0 & 25 & 30 & 8.0 & 4.4 & 102 & 5.8 \\
\hline
\end{tabular}

Figure 7. Rime Scaling (Case 460). 

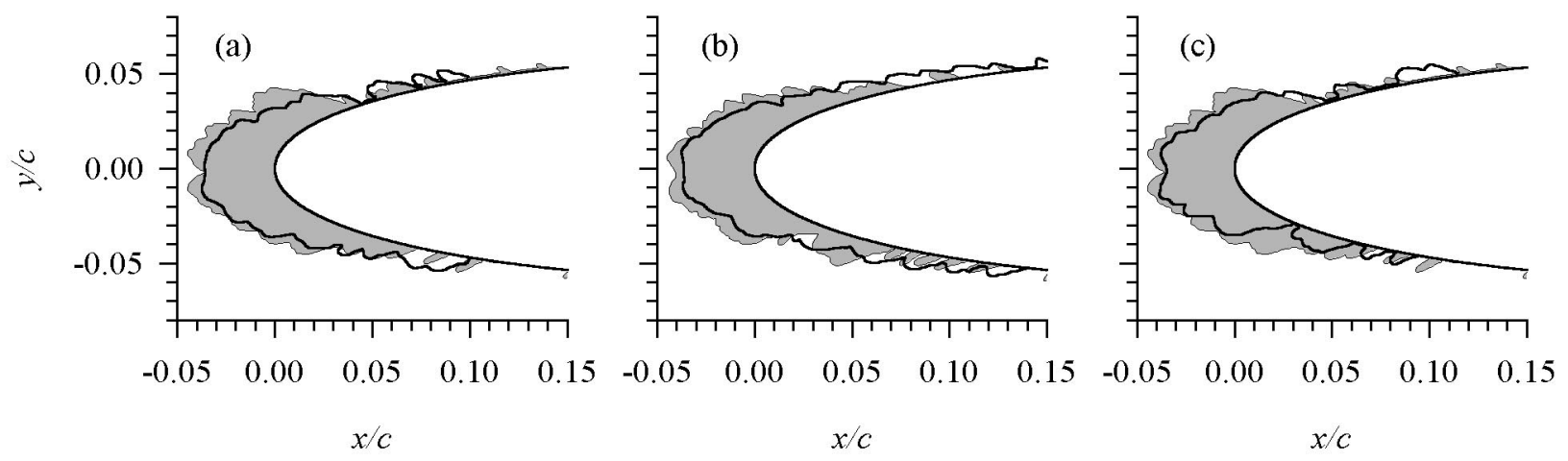

Reference $\longrightarrow$ Scale

\begin{tabular}{|c|c|c|c|c|c|c|c|c|c|c|c|c|c|c|c|c|c|}
\hline $\begin{array}{l}\text { Scaling } \\
\text { Method }\end{array}$ & Date/Run & $\begin{array}{c}c, \\
\mathrm{~cm}\end{array}$ & $\begin{array}{l}t_{s t} \\
{ }^{\circ} \mathrm{C}\end{array}$ & $\begin{array}{l}V, \\
\mathrm{~m} / \mathrm{s}\end{array}$ & $\begin{array}{c}M V D, \\
\mu \mathrm{m}\end{array}$ & $\begin{array}{l}L W C, \\
\mathrm{~g} / \mathrm{m}^{3}\end{array}$ & $\underset{\mathrm{min}}{\tau}$ & $K_{0}$ & $\begin{array}{l}\beta_{0}, \\
\%\end{array}$ & $A_{c}$ & $n$ & $\begin{array}{l}\phi, \\
{ }^{\circ} \mathrm{C}\end{array}$ & $\begin{array}{l}\theta, \\
{ }^{\circ} \mathrm{C}\end{array}$ & $\begin{array}{l}\text { Re, } \\
10^{4}\end{array}$ & $\begin{array}{l}\text { We } \\
10^{3}\end{array}$ & $W e_{h}$ & $\begin{array}{l}\text { rel } \\
h / d\end{array}$ \\
\hline (a) Ref & $11-13-00 / 7$ & 53.3 & -19 & 67 & 38 & 0.99 & 7.3 & 5.3 & 85 & 1.88 & 0.77 & 18 & 24 & 9.3 & 2.6 & 66 & 5.7 \\
\hline Const $W e$ & $11-16-00 / 13$ & 26.7 & -19 & 88 & 23 & 1.17 & 2.4 & 5.8 & 86 & 1.89 & 0.77 & 18 & 24 & 6.0 & 2.8 & 69 & 6.9 \\
\hline (b) Ref & $3-20-01 / 9$ & 53.3 & -19 & 67 & 40 & 0.99 & 7.3 & 5.7 & 86 & 1.89 & 0.77 & 18 & 25 & 9.2 & 2.8 & 66 & 5.7 \\
\hline Const $W e_{h}$ & $3-22-01 / 4$ & 26.7 & -20 & 86 & 24 & 1.18 & 2.4 & 5.8 & 86 & 1.90 & 0.78 & 19 & 24 & 5.8 & 2.7 & 67 & 7.0 \\
\hline (c) Ref & $11-13-00 / 7$ & 53.3 & -19 & 67 & 38 & 0.99 & 7.3 & 5.3 & 85 & 1.88 & 0.77 & 18 & 24 & 9.3 & 2.6 & 66 & 5.7 \\
\hline Const $h / d$ & $11-16-00 / 12$ & 26.7 & -20 & 114 & 21 & 0.92 & 2.3 & 5.7 & 86 & 1.88 & 0.77 & 18 & 22 & 7.6 & 4.2 & 98 & 5.8 \\
\hline
\end{tabular}

Figure 8. Scaling with $n=0.77$ (Case 461).

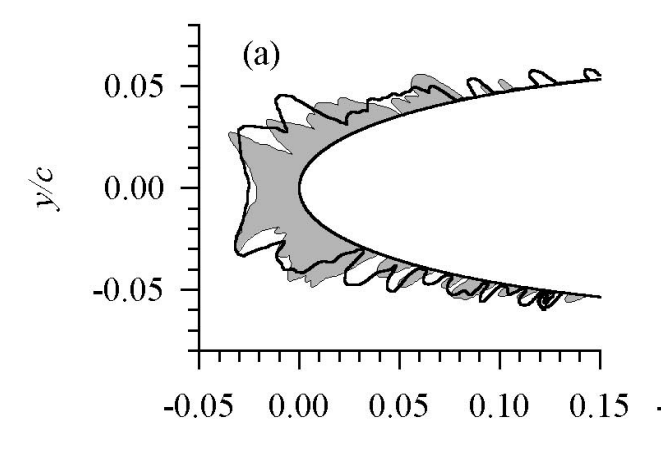

$x / c$
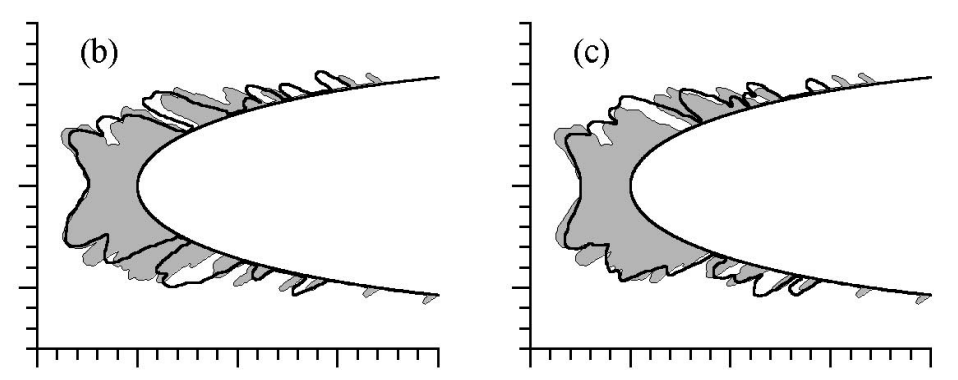

$-0.05$

$\begin{array}{lllll}-0.05 & 0.00 & 0.05 & 0.10 & 0.15\end{array}$

$x / c$

$x / c$

Reference $\quad$ Scale

\begin{tabular}{|c|c|c|c|c|c|c|c|c|c|c|c|c|c|c|c|c|c|}
\hline $\begin{array}{l}\text { Scaling } \\
\text { Method }\end{array}$ & Date/Run & $\begin{array}{l}c, \\
\mathrm{~cm}\end{array}$ & $\begin{array}{l}t_{s t}, \\
{ }^{\circ} \mathrm{C}\end{array}$ & $\begin{array}{c}V, \\
\mathrm{~m} / \mathrm{s}\end{array}$ & $\begin{array}{c}M V D, \\
\mu \mathrm{m}\end{array}$ & $\begin{array}{l}L W C, \\
\mathrm{~g} / \mathrm{m}^{3}\end{array}$ & $\begin{array}{c}\tau, \\
\min \end{array}$ & $K_{0}$ & $\begin{array}{c}\beta_{0}, \\
\%\end{array}$ & $A_{c}$ & $n$ & $\begin{array}{l}\phi, \\
{ }^{\circ} \mathrm{C}\end{array}$ & $\begin{array}{l}\theta, \\
{ }^{\circ} \mathrm{C} \\
\end{array}$ & $\begin{array}{l}\text { Re, } \\
10^{4}\end{array}$ & $\begin{array}{l}\text { We, } \\
10^{3}\end{array}$ & $W e_{h}$ & $\begin{array}{l}\text { rel } \\
h / d\end{array}$ \\
\hline (a) $\operatorname{Ref}$ & $3-20-01 / 5$ & 53.3 & -13 & 67 & 40 & 1.00 & 7.3 & 5.7 & 86 & 1.89 & 0.52 & 12 & 17 & 8.8 & 2.8 & 67 & 5.8 \\
\hline Const $W e_{h}$ & $3-22-01 / 7$ & 26.7 & -13 & 86 & 24 & 1.16 & 2.4 & 5.8 & 86 & 1.86 & 0.52 & 12 & 16 & 5.6 & 2.7 & 67 & 7.0 \\
\hline (b) Ref & $11-13-00 / 5$ & 53.3 & -13 & 67 & 38 & 0.99 & 7.3 & 5.3 & 85 & 1.88 & 0.52 & 12 & 17 & 8.9 & 2.6 & 67 & 5.8 \\
\hline $\operatorname{Avg} V$ & $11-16-00 / 8$ & 26.7 & -16 & 115 & 21 & 1.15 & 1.8 & 5.7 & 86 & 1.89 & 0.52 & 15 & 17 & 7.4 & 4.2 & 110 & 6.5 \\
\hline (c) Ref & $11-13-00 / 5$ & 53.3 & -13 & 67 & 38 & 0.99 & 7.3 & 5.3 & 85 & 1.88 & 0.52 & 12 & 17 & 8.9 & 2.6 & 67 & 5.8 \\
\hline Const $h / d$ & $11-16-00 / 6$ & 26.7 & -14 & 110 & 21 & 0.91 & 2.4 & 5.7 & 86 & 1.88 & 0.52 & 12 & 14 & 7.0 & 4.0 & 92 & 5.8 \\
\hline
\end{tabular}

Figure 9. Scaling with $n=0.5$ (Case 463). 
Figure 9(b) shows that again the average- $V$ approach provided an excellent match of the horn angle while also producing the correct ice quantity and simulating the feather region of the reference. Within typical shape repeatability, the results for the constant- $h / d$ method shown in figure 9(d) were also a very close simulation of the reference shape.

\section{Freezing Fraction of 0.40 (Case 464)-Figure 10}

For this freezing fraction, only the constant- $W e_{h}$, average- $V$ and constant- $h / d$ methods for determining scale velocity were evaluated. The best match of the reference shape and quantity occurred when scale velocity was found by the constant- $h / d$ method (fig. 10(c)). The constant- $W e_{h}$ method (10(a)) gave only an approximate simulation of the reference shape, while the average- $V$ method (fig. 10(b)) produced a poor simulation. Since typically the average- $V$ method produces successful scaling, the results of figure 10(b) need to be reexamined with additional tests before conclusions can be made.

\section{Freezing Fraction of 0.28 (Case 465)-Figure 11}

The warmest case tested was case 465 , which had a freezing fraction of 0.28 . Results for three of the four methods are given in figure 11. An idea of the variability of ice shapes accreted at freezing fractions this low can be seen from the results shown above in figures 5(a) and (b). Given the repeatability variations demonstrated by those two tests, it can be concluded that the constant- $W e_{h}$ (fig. 11(a)) scale test simulated the main ice shape acceptably well. The average- $V$ scale results in figure 11(b) do not appear to be a good simulation of the reference shape; however, figure 5(a) showed results from an earlier test entry for which the constant- $V$ scaling simulation at this freezing fraction was excellent. The constant-h/d method (fig. 11(c)) simulated the main ice shape well, although the scale feathers appear to be larger than for the reference test.

Additional tests at this freezing fraction are needed to better assess the constant- $h / d$ method. The preliminary assessment is, however, that any of the methods can produce acceptable scaling simulation for $n=0.28$. If scale simulations are needed at such low freezing fractions, it is recommended that, due to the variability of shapes, tests be repeated with more than one test entry.

\section{$\underline{\text { Summary }}$}

Measurements of the water-film thickness on a stagnation probe in cloud conditions simulating those of icing led to the non-dimensional thickness expression,

$$
h / d \propto\left(\frac{L W C}{\rho_{w}}\right)^{1 / 2} R e^{-1 / 4}
$$
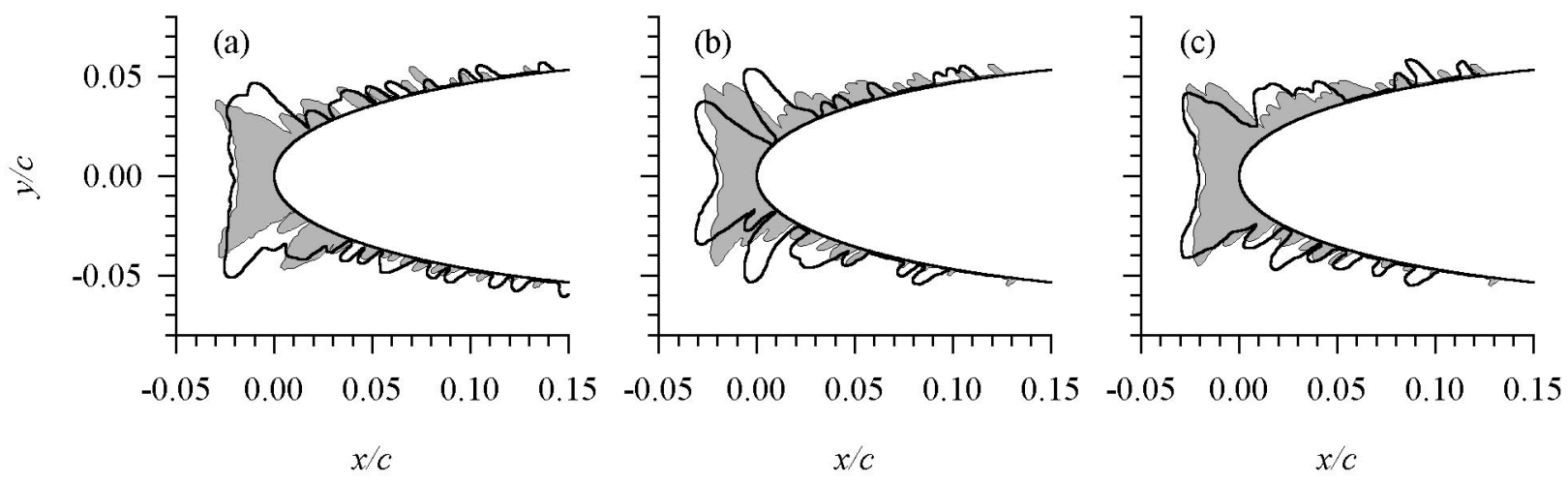

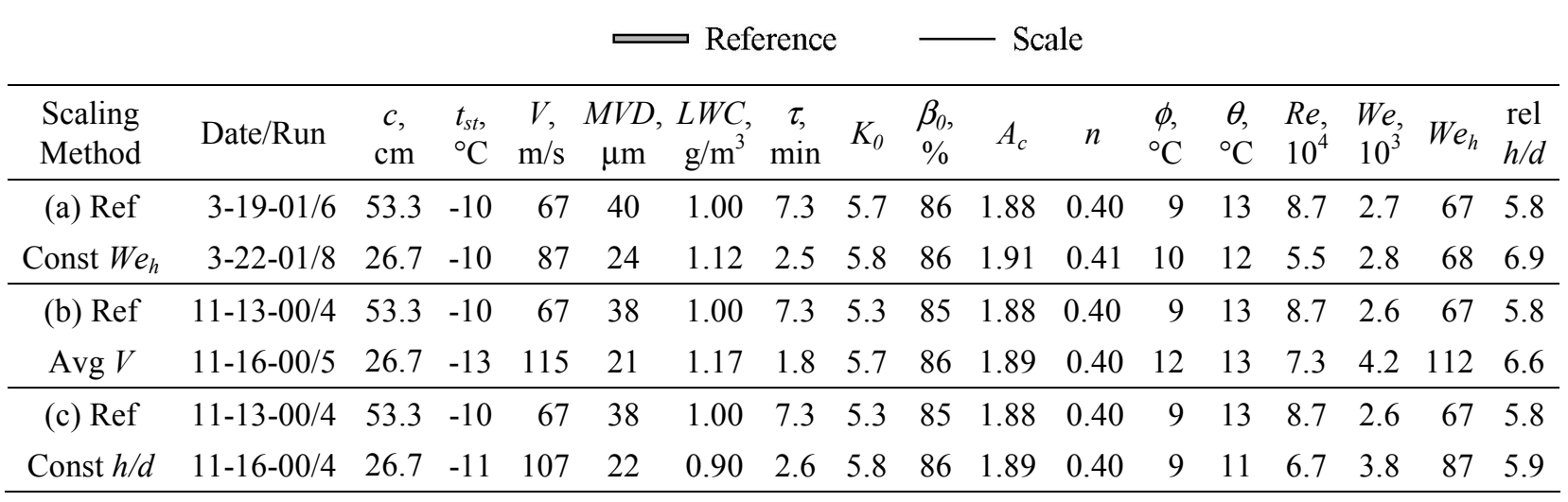

Figure 10. Scaling with $n=0.40$ (Case 464). 


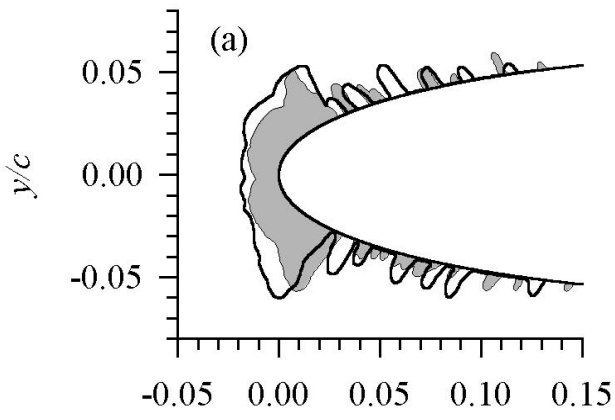

$x / c$

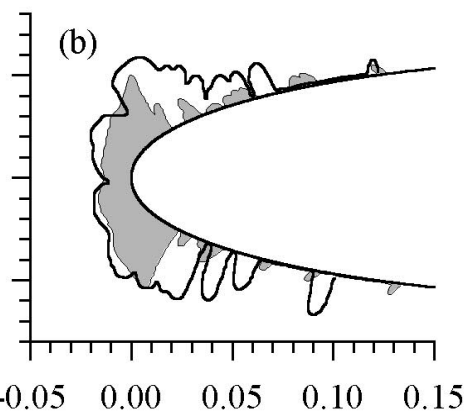

$x / c$

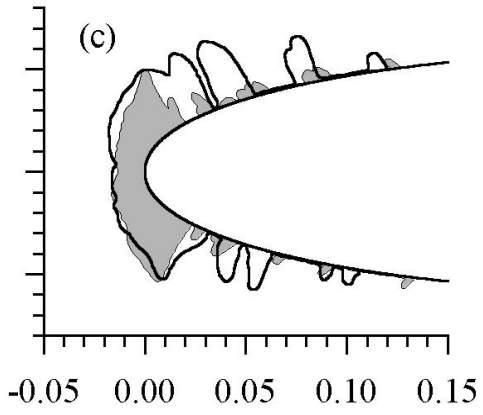

$x / c$

Reference $\quad$ Scale

\begin{tabular}{|c|c|c|c|c|c|c|c|c|c|c|c|c|c|c|c|c|c|}
\hline $\begin{array}{l}\text { Scaling } \\
\text { Method }\end{array}$ & Date/Run & $\begin{array}{c}c, \\
\mathrm{~cm}\end{array}$ & $\begin{array}{l}t_{s t}, \\
{ }^{\circ} \mathrm{C}\end{array}$ & $\begin{array}{c}V, \\
\mathrm{~m} / \mathrm{s}\end{array}$ & $\begin{array}{c}M V D, \\
\mu \mathrm{m}\end{array}$ & $\begin{array}{l}L W C, \\
\mathrm{~g} / \mathrm{m}^{3}\end{array}$ & $\underset{\min }{\tau}$ & $K_{0}$ & $\begin{array}{l}\beta_{0}, \\
\%\end{array}$ & $A_{c}$ & $n$ & $\begin{array}{l}\phi, \\
{ }^{\circ} \mathrm{C}\end{array}$ & $\begin{array}{l}\theta, \\
{ }^{\circ} \mathrm{C}\end{array}$ & $\begin{array}{l}\text { Re, } \\
10^{4}\end{array}$ & $\begin{array}{l}W e, \\
10^{3}\end{array}$ & $W e_{h}$ & $\begin{array}{l}\text { rel } \\
h / d\end{array}$ \\
\hline (a) Ref & $3-20-01 / 1$ & 53.3 & -7 & 67 & 40 & 1.00 & 7.3 & 5.7 & 86 & 1.89 & 0.28 & 7 & 9 & 8.5 & 2.7 & 68 & 5.8 \\
\hline Const $W e_{h}$ & $3-22-01 / 11$ & 26.7 & -8 & 88 & 23 & 1.06 & 2.6 & 5.8 & 86 & 1.90 & 0.29 & 7 & 8 & 5.5 & 2.8 & 68 & 6.7 \\
\hline (b) Ref & $11-13-00 / 2$ & 53.3 & -7 & 67 & 38 & 1.00 & 7.3 & 5.3 & 85 & 1.88 & 0.28 & 7 & 9 & 8.6 & 2.6 & 68 & 5.8 \\
\hline $\operatorname{Avg} V$ & $11-16-00 / 2$ & 26.7 & -10 & 114 & 21 & 1.20 & 1.8 & 5.8 & 86 & 1.87 & 0.29 & 9 & 9 & 7.1 & 4.2 & 114 & 6.7 \\
\hline (c) Ref & $11-13-00 / 2$ & 53.3 & -7 & 67 & 38 & 1.00 & 7.3 & 5.3 & 85 & 1.88 & 0.28 & 7 & 9 & 8.6 & 2.6 & 68 & 5.8 \\
\hline Const $h / d$ & $11-16-00 / 1$ & 26.7 & -8 & 102 & 22 & 0.87 & 2.8 & 5.8 & 86 & 1.90 & 0.28 & 7 & 7 & 6.3 & 3.5 & 79 & 5.9 \\
\hline
\end{tabular}

Figure 11. Scaling with $n=0.28$ (Case 465).

The expression on the right side of this proportionality was used as a relative $h / d$ scaling parameter, and a Weber number based on this relative water-film height, $W e_{h}$, was also used as a second scaling parameter to determine scale velocity to supplement the Ruff scaling method. Results from tests with either of these two parameters were compared with those from tests with constant $W e$ and average velocity, which have been discussed in previous papers. Scale test conditions found using the constant-We and constant- $W e_{h}$ methods were the same, within parameter uncertainty.

Each of the methods typically provided a good simulation of the size and density of the feather growth behind the leading-edge shape for all cases. However, the comparison of the main ice shapes near the leading edge revealed some differences in how well the various methods scaled the ice. The differences depended on the freezing fraction.

For rime ice $(n=1.0)$ there is no surface water and all methods of choosing scale velocity should produce the same ice shape. This was generally true, except that for the highest scale velocities, the relative quantity of scale ice was less than the reference. The deficit appeared to be within the $\pm 10 \%$ uncertainty in the IRT $L W C$ calibration, however.
At a freezing fraction of 0.76 , there was no significant difference in the scale ice shapes produced by the different methods. Scale accretions were somewhat smaller than the reference for all methods, but were within $10 \%$ of the reference size. For freezing fractions of $0.40,0.52$ and 0.61 , all methods resulted in scale accretions closely matching the size of the reference, but somewhat better agreement with the reference horn angles was typically achieved with the average- $V$ and constant- $h / d$ methods than with the constant-We or constant- $W e_{h}$. At a freezing fraction of 0.28 , the four methods were judged equal in providing simulations of the reference shape within the ice-shape repeatability. At low freezing fractions, poorer repeatability has been observed than for higher freezing fractions.

Conclusions of this study with regard to the constant$W e$ and average- $V$ methods of finding scale velocity agreed with those of reference 12 , in which those two methods were also tested. The conformity of the average- $V$ and constant- $h / d$ methods is consistent with the presumption that both $R e$ and $W e$ are important parameters in describing those water-film phenomena that affect ice accretion. 


\section{$\underline{\text { References }}$}

${ }^{1}$ Charpin, Francois and Fasso, Guy, "Essais de givrage dans la grande soufflerie de Modane sur maquettes a echelle grandeur et echelle reduite," L'Aeronautique et l'Astronautique, no. 38, 1972, pp. 23-31. English translation published as "Icing Testing in the Large Modane Wind-Tunnel on Full-Scale and Reduced Scale Models," NASA TM-75373, March 1979.

2 Ruff, G.A., "Analysis and Verification of the Icing Scaling Equations," AEDC-TR-85-30, vol. 1 (Rev), March 1986.

${ }^{3}$ Langmuir, Irving and Blodgett, Katharine B.: "A Mathematical Investigation of Water Droplet Trajectories," Army Air Forces Technical Report No. 5418, February 1946.

${ }^{4}$ Messinger, B.L., "Equilibrium Temperature of an Unheated Icing Surface as a Function of Airspeed," $J$. Aeron. Sci. vol. 20 no. 1, January 1953, pp. 29-42.

5 Tribus, Myron, Young, G.B.W. and Boelter, L.M.K., "Analysis of Heat Transfer Over a Small Cylinder in Icing Conditions on Mount Washington," Trans. ASME vol. 70, November 1948, pp. 971-976.

6 Bilanin, A.J., "Proposed Modifications to the Ice Accretion/Icing Scaling Theory," AIAA Paper AIAA88-0203, January 1988.

${ }^{7}$ Bilanin, Alan J. and Anderson, David N., "Ice Accretion with Varying Surface Tension," AIAA-95-0538 and NASA TM-106826, January 1995.

8 Kind, R.J., Dillon, T., Gaydos, J.A. and Oleskiw, M., "Evidence for the Importance of Scaling Viscous Effects in the Water Film in Glaze Icing Tests," AIAA98-0196, January 1998.

9 Kind, Richard J., "Assessment of Importance of Water-Film Parameters for Scaling of Glaze Icing," AIAA-2001-0835, January 2001.

10 Kind, Richard J., "Experimental Assessment of a Water-Film-Thickness Weber Number for Scaling of Glaze Icing," AIAA-2001-0836, January 2001.

11 Anderson, David N. and Ruff, Gary A., "Evaluation of Methods to Select Scale Velocities in Icing Scaling Tests," AIAA-99-0244, January 1999.

12 Anderson, David N., "Effect of Velocity in Icing Scaling Tests," AIAA-2000-0236, January 2000.
13 Mundo, C., Sommerfeld, M. and Tropea, C., "Droplet-Wall Collisions: Experimental Studies of the Deformation and Breakup Process," Int. J. Multiphase Flow, vol. 21, no. 2, 1995, pp. 151-173.

${ }^{14}$ Feo, A. and Urdiales, M., "Stagnation Point Probe in a Water Spray Immersed in an Airstream," $\phi A E / T N O / 0452 / 003 / I N T A / 95$, Instituto Nacional de Técnica Aeroespacial, February 1995.

${ }^{15}$ Feo, A., "Icing Scaling with Surface Film Thickness Similarity for High LWC Conditions," AE/PRO/4420/184/INTA/00, Instituto Nacional de Técnica Aeroespacial, October 2000.

${ }^{16}$ Feo, A., Rogles, F. and Urdiales, M., "The Measurement of Water Film Thickness on Airfoils in Heavy Rain Conditions Using Conductance Sensors," AGARD CP-496, December 1991.

17 Rothmayer, Alric, personal communication, May 2001 .

${ }^{18}$ Ide, Robert F. and Oldenburg, John R., "Icing Cloud Calibration of the NASA Glenn Icing Research Tunnel," AIAA-2001-0234, January 2001.

19 Irvine, Thomas B., Kevdzija, Susan L., Sheldon, David W. and Spera, David A., "Overview of the Icing and Flow Quality Improvements Program for the NASA Glenn Icing Research Tunnel," AIAA-20010229, January 2001. 


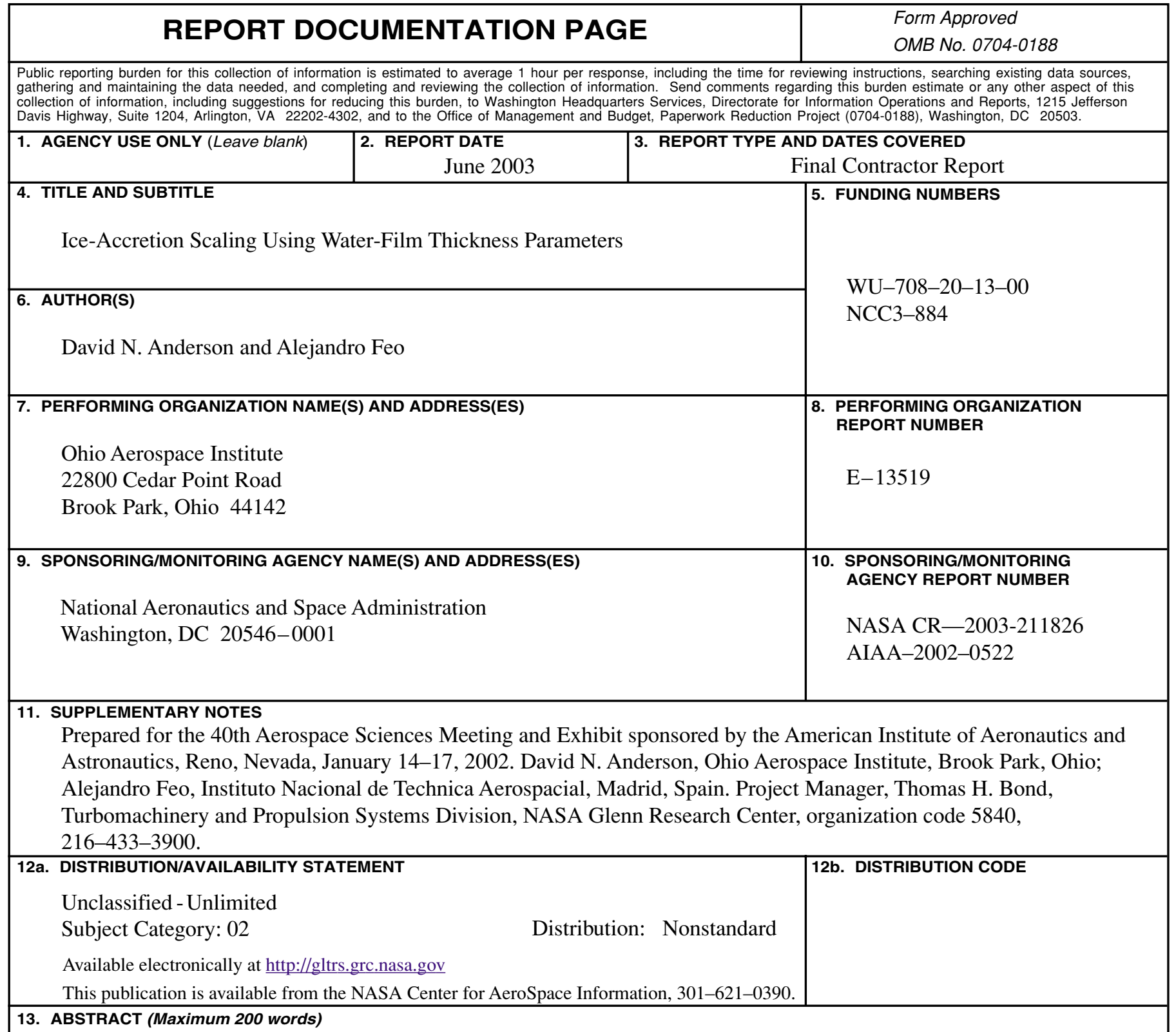

Studies were performed at INTA in Spain to determine water-film thickness on a stagnation-point probe inserted in a simulated cloud. The measurements were correlated with non-dimensional parameters describing the flow and the cloud conditions. Icing scaling tests in the NASA Glenn Icing Research Tunnel were then conducted using the Ruff scaling method with the scale velocity found by matching scale and reference values of either the INTA non-dimensional waterfilm thickness or a Weber number based on that film thickness. For comparison, tests were also performed using the constant drop-size Weber number and the average-velocity methods. The reference and scale models were both aluminum, 61-cm-span, NACA 0012 airfoil sections at $0^{\circ}$ AOA. The reference had a 53-cm-chord and the scale, $27 \mathrm{~cm}(1 / 2 \mathrm{size})$. Both models were mounted vertically in the center of the IRT test section. Tests covered a freezing fraction range of 0.28 to 1.0 . Rime ice $(n=1.0)$ tests showed the consistency of the IRT calibration over a range of velocities. At a freezing fraction of 0.76 , there was no significant difference in the scale ice shapes produced by the different methods. For freezing fractions of $0.40,0.52$, and 0.61 , somewhat better agreement with the reference horn angles was typically achieved with the averagevelocity and constant-film thickness methods than when either of the two Weber numbers was matched to the reference value. At a freezing fraction of 0.28 , the four methods were judged equal in providing simulations of the reference shape.

\begin{tabular}{|c|c|c|c|}
\hline \multicolumn{2}{|l|}{ 14. SUBJECT TERMS } & & $\begin{array}{c}\text { 15. NUMBER OF PAGES } \\
18 \\
\end{array}$ \\
\hline
\end{tabular}



